\title{
Application and analysis of SIL3 used in DCS system at HONGSA power plant 626MW unit in Laos
}

\author{
Fang Guocheng ${ }^{1}$, Cao Yang ${ }^{1}$, Ma Minghong ${ }^{1}$, Jin Longfei ${ }^{1}$ \\ 1 State Grid Liaoning electric power research institute
}

\begin{abstract}
It is mainly for security level problems of important protection items of modern thermal power plant in this article, the main protection including boiler protection and turbine protection and so on, make the standard of SIL used in the control system of thermal power plant, using SIL3 safety level to improve the safety level of the thermal power plant main protection, to ensure safe and stable operation of the whole thermal power plant, at the same time use Laos HONGSA power plant 626MW sub-critical unit as an example, explain further the application of SIL3 used in DCS system and control analysis, through actual parameters of the running unit prove the safety and reliability of the method.
\end{abstract}

\section{System introduction}

Now main protection of thermal power unit boiler and turbine main protection and other important items are belong to the same with DCS control system, it will occur the phenomenon of signals distortion due to important signals in the process of transmission, and easily to occur the phenomenon of protection disoperation or refusing action, seriously affecting the generator-turbine stable running and normally working, this paper proposes a new control method of main protection, using SIL3 safety level rating by the safety and reliability of the whole main protection system[1], and ensure the whole turbine unit can be running stable.

This unit turbine is sub-critical, single reheat, single shaft, 3-casing, 4-exhaust and condensing type turbine. It adopts reactive type of blade, integral forging rotor, multiple casings and DEH control system and so on. It has the advantages of compact structure, good economies, high efficiency and reliability. The boiler is produced by Harbin Boiler Co. Ltd, with type of HG2030/17.5-HM15 subcritical parameter, П-type open layout, Lignite as design coal, single furnace Octagonal combustion, medium single reheat, balanced ventilation, full steel frame suspension structure, and dry ash. Control cycle drum boiler.

Except that mechanical type over speed protectors and electronic type over speed protectors are provided in protection system of the turbine, the emergency trip system (ETS) is mainly used for checking correctness of all signals requiring tripping, identifying error tripping signals, and implementing tripping commands effectively land rapidly when dangerous conditions occur on the equipments. The turbine bypass system is a system in which high-low pressure serial bypass systems are provided and capacity of the system is $70 \% \mathrm{BMCR}$.

The unit is controlled by using I/A DCS of ABB Company. The Turbine supervision system (TSI) can continuously measure all mechanical operation parameters of shaft and cylinder of the turbine, and issue alarm signals and trip the unit when set points of operation are exceeded.

Main parameters of the unit:

Continuous output:626MW

Speed:3000rpm

Rotating direction: clockwise

Main steam pressure: $16.7 \mathrm{Mpa}$

Main steam temperature: $538^{\circ} \mathrm{C}$

Back pressure: $0.008 \mathrm{Mp}$

Reheat stages: 8 stages

Type of control system: DEH

Maximum allowable system cyclic vibration: $48.5 \sim 50.5 \mathrm{~Hz}$

Rated speed variation during idling operation \pm 1

Stages for flow path:44

Stages of HP turbine:I+9

Stage of IP turbine: 6

Stage of LP turbine: $2 \times 2 \times 7$

Length of L-0 blade: $1000 \mathrm{~mm}$

Turning gear speed:3.35 rpm

Total length of turbine: $27800 \mathrm{~mm}$

Maximum width of turbine: $11400 \mathrm{~mm}$

Weight of turbine proper: $1108 \mathrm{t}$

\section{SIL system security level analysis}

SIL (Safety Integrity Level) is to point to in a certain time and certain conditions, the possibility of the safety related 
system to perform its specified security features. In standard IEC61508, safety integrity level is divided into four grades, and level 4 is the highest, level 1 is lowest, level of SIL comes higher is meaning the probability of safety function is more higher that safety instrument system can be realized[2-5].

SIL is one of the important indicators to measure safety integrity, and used to evaluate safety system in a certain time and certain conditions to perform the provisions of the probability of safety function[6]. Confirm SIL is sure need to confirming the lowest reaction the possibility of failure, make the equipment can successfully when there is a need for design requirements of the safety function[7-10]. For general control in the industry process control, the common level of SIL is SIL2 and SIL3, so for thermal power industry control, application of SIL3 safety level is the highest level standard in the probability of system security functions, SIL3 safety level used in coal-fired power plant main protection control, completely can ensure the stable and safety running of the steam turbine generator unit.

\section{SIL system controlling analysis}

Using the security level of SIL to control the main protection items of power plant, first of all have to confirm the SIL system hardware configuration, depending on the requirement of the system and the hardware configuration, for software configuration, etc, and the hardware configuration must be according to the design parameters of the thermal power plant and the number of important equipment to decide, mainly according to the running signal or stopped the signal of the important running equipment to determine the number of input cards and output cards of the SIL system, then determine the types and number of controller and power supply, the important equipment of the unit is as follows:

The turbine is provided with two high pressure main steam valves, four high pressure adjustment steam valves, two middle pressure main steam valve and four middle pressure adjustment steam valves. The through flow part of the unit comprises total forty eight grades, in which one single column impulse stage +11 pressure reverse impulse stages for high pressure cylinder, eight pressure reverse pulse stages for middle pressure cylinder, and $2 \times 2 \times 7$ pressure inverse pulse stages for low pressure cylinder. All of high, middle and low pressure rotors are alloy steel rotors free of central hole. Stiff connection is adopted for all of high and middle pressure rotors, two low pressure rotors and generator rotors.

Each boiler equipped with 8 MFH4112 ( MB4100/1250/420) fan mills direct-fired system, 8 sets of weighing belt feeders TZ-SC04500 and 8 sets of center feeders are equipped, six sets in operation, one for spare and one for maintenance, 6 feeders can satisfy the request of coal quantity when designed coal is burned There are 40 low NOx burners which apply 8 corners tangential arrangement, and the boiler runs in BMCR condition.
The important equipment of boiler sub-system is including: two APH, and one APH is composed of main motor and the auxiliary motor, two sets of induced draft fan, two blowers, eight fan mills, two cooling fan flame detectors, three sets of furnace water circulating pump; the important equipment of turbine sub-system is including: two condensate pumps, two sets of circulating water pump and one circulating pump divided into low and high speed two operation modes and can switch each other, two steam driven feed water pumps and an motor driven feed water pump, two sets of EH oil pump, two sets of vacuum pumps, two sets of closed circulating water pumps, two lubricating oil pumps and four sets of seal oil pump.

According to the above parameters, SIL3 system is configured with 16 pieces of digital input cards and four digital output cards, each input card sets 16 input channels, namely each card can accommodate up to 16 input signals, each output card sets 16 channels, can send 16 output signals, two lines control power supply and its corresponding power supply module, two way communication control module and two-way controller, in order to realize the redundant functions. The parts of system hardware are as shown in Figure 1, Figure 2:

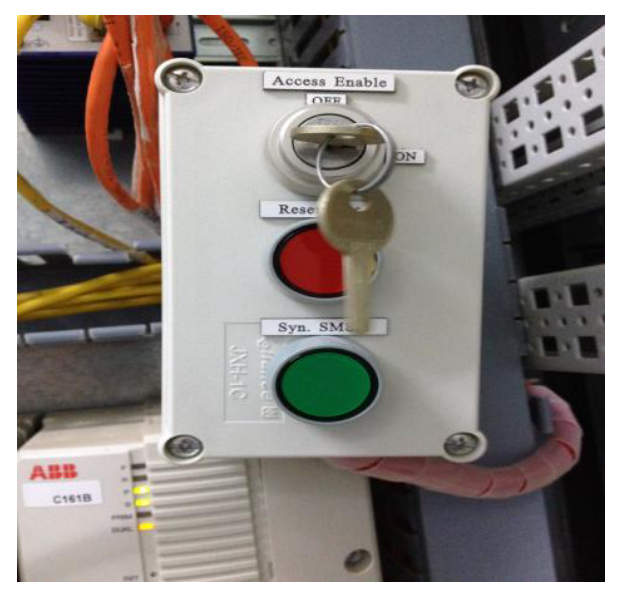

Figure 1. SIL3 system control button

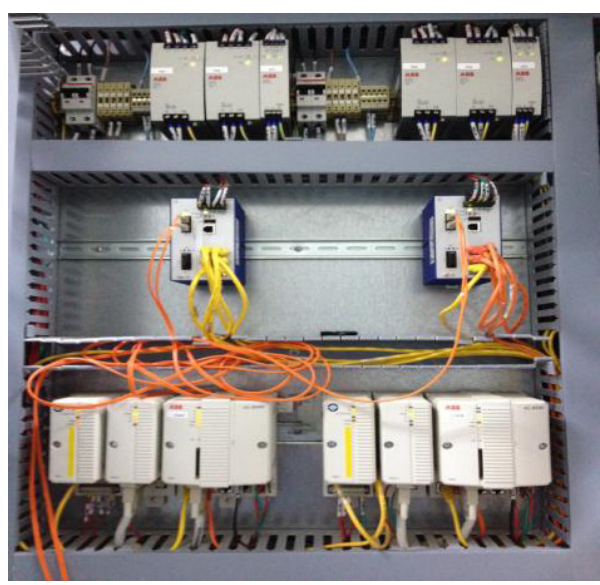

Figure 2. SIL3 system hardware 


\section{Based on the analysis of control application}

\subsection{SIL3 the bottoms of the controller}

Choose AC800M controllers, the content of the configuration bottoms: first set the controller IP address, include: open the IPConfig; The serial port wiring is connected from the controller Com4 port to the local computer serial port[11-13]. In IPConfig option to choose the connected computer serial port name; After connected the Make a Controller system reset is on, suggest to initialize the Controller, namely, long press on the Controller Init, until R light flashes, when the system detects that the controller has been initialized, a system reset detected waiting on the controller startup; Select the Advanced Mode and setting main network IP, check the Enable Auto restart, and then click Set IP to set the IP address; Choice Set Backup IP addresses setting auxiliary network IP, redundant controller of auxiliary network IP to the main controller of auxiliary network IP add 2, on the basis of the choice set IP setting[14,15].

\subsection{The analysis of the SIL3 configuration}

Variable and function block naming principles: according to the variable action divides: local variables begin with 1_ (variable); Global variables (external variable) begin with e_; Constants starting with $p_{-}$. Need a unified definition of commonly used variables: (1) Time variables: define the commonly used time, type of time, mainly used for the delay and the pulse function, from $1 \mathrm{~s}$ to $10 \mathrm{~s}$, named TIME01 to TIME10. (2) Logic variables: common logic variables, named booll and boo10. (3) The alarm level variables: corresponding PGP alarm levels. Named PRI1 to PRI5. For global variables, and reference is reference must be in the External variable definition, all other global variable must be defined in the Application. The part of the unit control logic is as shown in Figure 3, part of the operation screen is as shown in Figure 4:

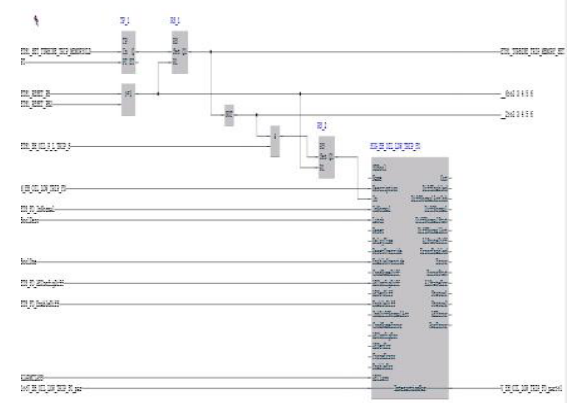

Figure 3. Parts of SIL3 control logic

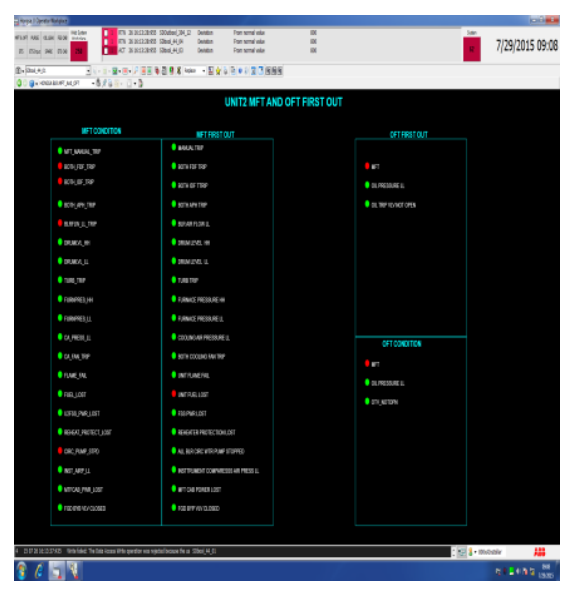

Figure 4. Parts of SIL3 control graph

\subsection{SIL3 commonly used settings}

(1) Backup and restore: can be directly copy project folder backup recovery, but the instruction can select the realization of the backup. (2) The differences report: when the configuration changes through differences report on whether to implement the configuration of the switch[16]. (3) Compilation matters set: select Settings of Complier Switches, if exist in the logic loop (e.g., test process), you need to Loops in ST and Loops in the Control Modules for Allowed, otherwise can't bottoms.

\section{Conclusion}

SIL3 safety level is the highest level in the applications of thermal power plant control, its application in DCS system control, fully able to ensure the whole boiler and turbine set can be working normally and safety operation, through the practical application units, the advantages of its control is as follows: system takes up little resources; Speed fast, complete code editor can be used, do not need to compile, manual code than compiled code is more concise; Processing can be achieved by Excel variables list, and copy and paste to and fro, and the whole project is located in one folder, do not need to import and export operation, easy to backup.

\section{Acknowledgement}

This project is supported by 2015 young people and the mass innovation project fund in State Grid Corporation of China.

\section{References}

1. Liu S X. Safety Integrity Level introduction. Control engineering china, 9 (2006)

2. Chen H, Jia Y, Xu X L. The Application Study of Safety Integrity Level Analysis Methods. AUTOMATION IN PETRO-CHEMICAL INDUSTRY 47, 1 (2011)

3. CURRIE M. Operator Experience of SIL Determination in the Of $\mathrm{f}$ shore Oil and Gas Industry // Institution of Electrical Engineers, Seminar on 
Methods and Tools for SI L Determination. London: IEEE, 2005:18

4. Wang Y H, Wang Q Y, Fu X H. SIL Determination in Designing Safe Instruments for Nature Gas Dehydration Unit. Control and Instruments in Chemical Industry 39, 1 (2012)

5. Lv L. Comparison of Technologies for Safety Integrity Level Determination, Control and Instruments in Chemical Industry 40, 5 (2013)

6. Zhou R Y, Zhong A, Ren J Z. Comparative study on determining methods for safety integrity level of safety system, Journal of Safety Science and Technology 10, 3 (2014)

7. Feng X S. Techniques for SIL determination based on risk, Instrument Standardization and Metrology, 3 (2006)

8. Guo H T, Yang H. Safety integrity level of safety related system and its selection, Control and Instruments in Chemical Industry 33, 2 (2006)

9. Chen H, Jia Y, Xu X L. The application study of safety integrity level analysis methods, Automation in Petro-chemical Industry 47, 1 (2011)

10. Xu Z Y. Evaluation of Safety Integrity Level for Safety Instrumented System, Control and Instruments in Chemical Industry 36, 5 (2009)

11. Li Y M, Jiang W W, Li R Q. Estimating Technology of Safety Integrity Level of Safety Instrumented System, Security control technology , 3 (2010)

12. Jiang, W W, Li Y M. Application of Estimating Technology of Safety Integrity Level of Safety Instrumented System, CHINA INSTRUMENTATION, 2 (2009)

13. Guo H T, Yang X H. Quantitative Method for SIL Assignment of Safety Instrumented System, Control and Instruments in Chemical Industry 33, 6 (2006)

14. STAVR IANIDIS P, KBH IMAVARAPU $K$. Perform acerbated Standards: Safety Instrumented Functions and Safety Integrity Levels, Journal of Hazardous Materials 71, 1 (2000)

15. Li R Q. Study of Estimating Technology of Safety Integrity Level of Safety Instrumented System, China University of petroleum, 5 (2011)

16. Stavr I P, Kbh I K. Safety Instrumented Functions and Safety Integrity Levels (SIL), ISA Transactions, (1998) 